Calkins, S. D., Propper, C.B., \& Mills-Koonce, W. R. (2013). A biopsychosocial perspective on parenting and psychopathology. Development and Psychopathology. 25(4 pt2), 1399-1414. Made available courtesy of Cambridge University Press:

\title{
A biopsychosocial perspective on parenting and developmental psychopathology
}

\author{
SUSAN D. CALKINS,${ }^{a}$ CATHI PROPPER,${ }^{b}$ AND W. ROGER MILLS-KOONCE ${ }^{b}$ \\ ${ }^{a}$ University of North Carolina at Greensboro; and ${ }^{b}$ University of North Carolina at Chapel Hill
}

\begin{abstract}
Although considerable research has examined the relations between parental behavior and a range of child developmental outcomes, much of this work has been conducted at a very broad level of behavioral analysis. A developmental psychopathology framework and recent research conducted within this framework point to the need for models of parenting and child psychopathology that offer greater specificity regarding processes that may be implicated in the effects of these relationships. In addition, recent animal work and some human work has focused more on the proximal biological and social mechanisms through which parenting affects child outcomes. Our conceptualization of parenting effects acknowledges that family and child factors are embedded in a dynamic biological and social context that is key to understanding developmental trajectories of child adjustment. In this paper, we review two areas of research that are illuminating the biological processes underlying links between parenting and child psychopathology: molecular genetics and psychophysiology. We adopt a biopsychosocial perspective on developmental psychopathology that implies that a set of hierarchically organized, but reciprocally interacting, processes, from the genetic to the environmental, provide the essential elements of both normative and nonnormative development (Gottlieb, 2007). New directions stimulated by this general approach are discussed, with an emphasis on the contextual and developmental issues and applications implied by such a perspective.
\end{abstract}

Although there have been a number of different conceptual and empirical approaches to the study of the effects of parenting on child adjustment, such work is often conducted from within a developmental psychopathology framework (e.g., Cummings, Davies, \& Campbell, 2000; Rutter \& Sroufe, 2000). This perspective suggests that there are multiple contributors to maladaptive and adaptive outcomes, that these contributors may interact in various ways within different individuals, and that the consequences for development are multiple pathways to disordered behavior and/or multiple variants of outcome from individual causative factors (Cicchetti, 1984; 1993; Cicchetti \& Rogosch, 1996; Sroufe \& Rutter, 1984). Cicchetti and others (Cicchetti \& Rogosch, 1996; Richters, 1997) have described these perspectives as multifinality and equifinality. This perspective also highlights the need for complex, process-oriented models of development and emphasizes the importance of conducting longitudinal investigations of the factors that may both influence and be influenced by early contextual, familial, or individual difference factors. Finally, a developmental psychopathology perspective advocates an organizational view of development; multiple factors, or levels of a given factor, are considered in the context of one another rather than in isolation (Cicchetti \& Dawson, 2002).

Address correspondence and reprint requests to: Susan D. Calkins, Department of Human Development and Family Studies, P.O. Box 26170, University of North Carolina at Greensboro, Greensboro, NC 27402-6170; Email: sdcalkin@uncg.edu.
Current research on child psychopathology conducted within a developmental psychopathology framework has been informed by a large literature on the family factors that influence child adjustment versus maladjustment (Cummings et al., 2000). Much of this extant research has focused specifically on parenting behavior as a causal factor in the emergence of problematic child behavior. The general but consistent finding that emerges from this literature is that poor quality parenting is a significant risk factor for childhood psychopathology (Rothbaum \& Weisz, 1994). Much of this work has addressed the role of harsh, controlling parenting and the emergence of childhood externalizing problems, including aggression, oppositional behavior, and conduct problems (Gershoff, 2002; Patterson, Reid, \& Dishion, 1992). Other work has examined the role of factors that moderate parenting, including characteristics of the child, such as temperament (Bates, Pettit, Dodge, \& Ridge, 1998) and biological vulnerability (Erath, El-Sheik, Hinnant, \& Cummings, 2011).

As the literature examining parenting and child psychopathology has grown, there has been a shift in its emphasis and in several different directions. Early work focused on parenting and parent functioning as risk factors, with descriptive empirical work largely emphasizing main effects. Speculation on the developmental processes and specific mechanisms involved was often absent. Recent work has been more process-oriented, acknowledging that the relations between caregiving and child functioning were dynamic and transactional and often resulted in multiple pathways and different outcomes (Cummings et al., 2000). Greater emphasis 
has also been placed on the actual mechanisms that might be involved, observing that, although parenting does affect child functioning, greater attention needed to be paid to how parenting affects child adjustment outcomes (Davies \& Cummings, 1998). More attention has focused on the specific developmental pathways that are observed with respect to different, individual dimensions of both parenting and child outcomes (Meunier, Bisceglia \& Jenkins, 2012). Finally, as the developmental psychopathology framework became instantiated in research, it was clear that the biological level of analysis needed to be incorporated into empirical work and in a much more nuanced way than using traditional correlational and extreme group approaches (Hill-Soderlund et al., 2008).

Thus, although historically the emphasis on developmental pathways to child psychopathology has been on the role of family processes, growing interest has focused on the biological processes implicated in emerging child behavior more generally and in competencies and maladjustment in particular. For example, behavior genetics research has clearly stimulated growing appreciation for the role of genetic processes in emerging child psychopathology (cf. Horwitz \& Neiderhiser, 2011). This appreciation has already led many developmental scientists to reconfigure their models of development to incorporate both genetic and other biological processes as factors in the emergence of complex behavior (Sameroff, 2010; Shonkoff, 2010). Much of this theory building in developmental psychopathology has also been informed by existing conceptual and empirical work in the discipline of developmental psychobiology, an approach that is interdisciplinary and integrative, combining perspectives from evolutionary and developmental biology and physiology with subdisciplines of psychology to address questions about behavior and its development in humans and nonhuman animals (Michel \& Moore, 1995). It is this perspective that has had a major influence on subsequent empirical investigations of family processes that have adopted the tenets of developmental psychopathology (cf. Propper et al., 2008). This conceptual integration has led to greater appreciation of the complex role of biological processes in transactional models of development that seek to account for the emergence of patterns of adjustment and maladjustment across multiple levels of child functioning.

Psychobiological approaches to the study of early behavioral development, whether animal or human, remind us that a range of biological mechanisms are implicated in functioning at all levels of analysis. Gottlieb's depiction of probabilistic epigenesis (cf. Gottlieb, 1991, 2007) exemplifies the approach; it describes the changes that occur across developmental time in genetic, neural, behavioral, and environmental levels of analysis and depicts the bidirectional effects across time from one level to another. Gottlieb's model has stimulated both conceptual and empirical work aimed at providing greater specificity with regard to how the broad model may be instantiated to explain human developmental phenomena. Some of this work has attempted to "unpack" the action within and across levels to describe, for example, how gene action at the level of cellular activity occurs and influences numerous types of neural processes, some of which may ultimately be involved in producing complex behavior (Johnston \& Edwards, 2002) of the sort that is often referred to as child adjustment outcomes. Recent empirical work has also adopted Gottlieb's approach and begun to measure transactions across two or more of these biological levels, for example, from the gene (through molecular genetic analyses that specify candidate genes) to specific physiological processes (like parasympathetic regulation of cardiac output under stress) and how these relations may be moderated by dimensions of the environment, such as parenting across time (cf. Propper et al., 2008). Regardless of the focus of the research or the levels described or assessed, the underlying assumption in this work is the same: Genes initiate developmental pathways that are receptive to influences that occur from the cellular to the social contextual level, and all are candidates for developmental interactions that may influence pathways to child outcomes (cf. Cicchetti, Rogosch, \& Thibodeau, 2012). Thus, coaction, transaction, and interaction across levels characterize development in a biologically informed model of child, and thus family, functioning (Sameroff, 2010).

A biopsychosocial model motivates multilevel research that incorporates biological and behavioral indicators of the factors that may be implicated in complex developmental pathways to outcomes such as child psychopathology. Here, we review some of the research that informs such an approach. We focus on two pathways to child psychopathology: those in which genetic processes are moderated by the caregiving environment and those that examine physiological processes as a mediator of caregiver behavior and child outcomes.

\section{Genes, Environments, and Their Interaction}

It is well established that parental psychopathology and impaired parent-child relationships are among the primary risk factors for compromised child emotional and behavioral health (Cummings et al., 2000). However, there is variation in the extant literature regarding the nature and strength of this link between family processes and specific mental health outcomes. Although some children who are exposed to poorquality parenting early in life develop symptoms of psychopathology over time, many others do not. One reason for this discrepancy may be the influence of child genotype on outcomes; specific genetic effects on phenotypes may be conditional on particular environments and experiences and be unobserved under other conditions. Alternatively, exposure to certain experiences and environments may be influenced by the child's genotype (e.g., the way others behave toward them; activities they choose or that caregivers choose for them). It has become increasingly clear that child development and adjustment cannot be understood without taking into account both genes and environment as well as the relationship between them. Although there are several ways in which genotypes (measured at the molecular level) and environments may work together (Moffitt, Caspi, \& Rutter, 2006) 
to influence outcomes, here we focus on examples of just one, Gene $\times$ Environment interactions $(\mathrm{G} \times \mathrm{E})$.

Although behavioral genetics studies laid the groundwork for what we know about the unique influence of genes and the environment on childhood behavior (see review by Horwitz \& Neiderhiser, 2011), it is only relatively recently that we have been able to examine the influence of specific genetic alleles on behavior. This molecular genetics approach, which attempts to make associations between specific genes that regulate neurotransmitter systems and complex behavioral traits, provides more precise information about which genes may affect the development of both normal and pathological behaviors and possibly by what mechanism such effects occur. However, progress in this area has been hampered by the large number of mixed findings and failed replications. One reason for the difficulty in replicating genetic effects on complex behavioral outcomes is the lack of attention paid to environmental or experiential factors. Genes and environmental factors, or life experiences, must be considered from very early in development, because the bidirectional relationship between them may place individuals on distinct trajectories that will affect long-term development of mental health and disorders.

Over the past decade, researchers have embraced the importance of measuring both genes and environments and their interplay in order to predict both normative and pathological outcomes. Although some of these have focused on more distal factors (e.g., family social support, socioeconomic; Sadeh et al., 2010; Tucker-Drob \& Harden, 2012), there have been a number of studies that have focused on the critical environmental context of the caregiving experience. The first such investigations were done with nonhuman animals and retrospective studies of human adults. Several pioneering animal studies focused on the serotonin transporter gene, due to diminished serotonin transporter gene (5-HTT) transcription, lower transporter levels, and reduced serotonin uptake, with functional effects on neural circuits regulated by serotonin for those animals possessing the short allele (Hariri et al., 2002). Several findings revealed that rhesus monkeys who were raised by peers, rather than mothers, exhibited more behavioral and physiological problems (i.e., alcohol consumption, stress reactivity) and deficits in self-regulation (e.g., impulsivity, inappropriate aggression, orienting problems, risk taking) if they possessed the risk allele of the 5-HTT linked polymorphic region (5-HTTLPR; short/short or short/long) instead of the nonrisk allele (long/long). These findings suggest that poor quality early experience was only predictive of maladaptive outcomes for monkeys at genetic risk. For those monkeys who experienced a natural and supportive motherinfant relationship there was no effect of genotype (Barr et al., 2004; Bennett et al., 2002; Champoux et al., 2002; Suomi, 2004, 2005, 2006).

Similarly, in two landmark studies of $\mathrm{G} \times \mathrm{E}$ in human adults, Caspi et al. (2002) found that early adverse experience alone did not predict adult psychopathology. As with the animal studies described above, adults carrying the risk (short/ short or short/long) allele of serotonin were more likely to be depressed when they experienced stressful life events than were adults without the short allele or those with the short allele who did not experience stressful life events (Caspi et al., 2003). In addition, another study by this group found childhood maltreatment alone did not predict antisocial behavior in adulthood but that there was a significantly higher chance of developing later antisocial behavior for those individuals who possessed the risk allele of the functional polymorphism of the monoamine oxidase A $(M A O A)$ gene and also experienced maltreatment. Although these studies were the first to find such gene-environment interactions within a molecular genetics framework, a number of other studies followed attempting to replicate and extend these results to include other genes and environments across various developmental stages. In some cases findings were replicated (Foley et al., 2004; Frazzetto et al., 2007; Kim-Cohen et al., 2006; Widom \& Brzustowicz 2006), and in others they failed to replicate (Haberstick et al., 2005; Huizinga et al., 2006; Young et al., 2006), again suggesting the need to take unmeasured environmental factors into account. Although animal and adult human studies laid the groundwork for this area of study, the way in which $\mathrm{G} \times \mathrm{E}$ processes predict childhood behavior and maladaptive outcomes is still in the early stages. Two ways in which the field has attempted to apply a $\mathrm{G} \times \mathrm{E}$ approach to understand the emergence of childhood psychopathology is via $\mathrm{G} \times \mathrm{E}$ studies that (a) predict infant, toddler, and early childhood characteristics and behaviors, often associated with temperament or self-regulation, that are known to be precursors of later psychopathology, or (b) directly predict pathological outcomes in middle to late childhood.

\section{$G \times E$ influence on infant and toddler temperament and behavior}

Behavioral processes that emerge and develop over the first years of life are critical for subsequent adaptive social behavior, and thus it is important to understand the development of these early child-level factors that may be precursors for later psychopathology (Calkins \& Dedmon, 2000; Calkins \& Fox, 2002). Many of these processes fall under the rubric of temperament, defined as individual differences in reactivity and regulation (Rothbart, Ahadi, \& Evans, 2000), a construct believed to be a proxy for genotype but which, for the most part, has been studied behaviorally or via behavior genetic designs, such as twin or adoption studies (Goldsmith \& Hewitt, 2003; Goldsmith, Lemery, Buss, \& Campos, 1999). Recent advances in molecular genetics have led to the identification of alleles of specific genes that may underlie domains of infant and child temperament (e.g., effortful control; Posner, Rothbart, \& Sheese, 2007), but only a few investigations have looked at parenting as a moderator of the relationship between genes and behavioral outcomes with success (e.g., self-control; Wright, Schnupp, Beaver, Delisi, \& Vaughn, 2012; noncompliance; Sulik et al., 2012) and without success (e.g., effortful control; Sheese, Voelker, Rothbart, \& Posner, 2007). 
For example, behavioral inhibition (a fearful temperament or style of reacting when confronted with novelty) has been identified as a precursor of psychopathology in young adulthood (Caspi, Moffitt, Newman, \& Silva, 1996). The first study to predict behavioral inhibition using a $\mathrm{G} \times \mathrm{E}$ model found that children with the risk allele of the polymorphism in the promoter region of the serotonin transporter 5-HTT gene and low levels of social support early in life were at increased risk for behavioral inhibition at 7 years of age (Fox et al., 2005). However, although low levels of social support are theoretically associated with greater difficulties in parenting, this study did not measure the specific parenting behaviors that may have mediated the relationship between social support and behavioral inhibition.

More recently, a study linking another gene, the $M A O A$ length polymorphic region (MAOA-LPR, a 30 base pair repeat in the promoter region of $M A O A$ that affects transcriptional efficiency), to behavioral disinhibition in childhood aimed to identify specific experiences that may moderate the relationship and differentiate between the influence of a broad array of early family adverse experiences and stressful life events experienced in utero to 7 years of age (Enoch, Steer, Newman, Gibson, \& Goldman; 2010). Although this study also did not directly examine parenting, it provides an example of the way in which experience (related to the family or caregiving environment) may interact with genotype. Stressful life events, measured here as the sum of impact scores on 15 to 18 different stressful life events ranging from low to extreme severity (e.g., pet died, new sibling, physical hurt, sexual abuse) and family adversity operationalized as the sum of such experiences as maternal psychopathology, interparental cruelty, parental substance misuse, and at risk/taken into care, were examined in conjunction with $M A O A$. Several complex interactions were revealed: the low activity allele of $M A O A-L P R$ was associated with hyperactivity at ages 4 and 7 years for girls exposed to more stressful life events between 6 months and 3.5 years. Boys showed a slightly different timing pattern: Low activity MAOA-LPR interacted with stressful life events between ages 1.5 and 2.5 to predict hyperactivity at age 7. In contrast, behavioral disinhibition was not predicted by any interactions between early-life family adversity and MAOA-LPR (although family adversity over the first year of life did lead to more hyperactivity at ages 4 and 7). The authors conclude that it may be the first year of life when children are most susceptible to family adversity and in the first 3 years when stressful life events matter most. These findings emphasize the complexity of examining $\mathrm{G} \times \mathrm{E}$ interactions to predict behavioral outcomes from a developmental perspective. It appears that different types of difficult experiences (here divided into "stressful life events" and "family adversity") may interact with genes at different time points during development differently for males and females to influence behavior. Understanding these timing effects has important implications for developing appropriate preventions and interventions.

Other domains of infant temperament and behavior have also been the focus of $\mathrm{G} \times \mathrm{E}$ analyses. In one study, sensation seeking over the first 2 years of life was studied in children 18 to 21 months of age possessing the risk polymorphism of the dopamine receptor D4 gene ( $L-D R D 4)$ of the DRD4 exon III variable number tandem repeat gene (a 48 base pair repeat; Sheese et al., 2007). Those children whose mothers were observed as less sensitive caregivers exhibited more sensation seeking behavior (as reported by the mother) than did children possessing the $S$-DRD4 allele or with the $L-D R D 4$ allele who had more sensitive mothers. It is interesting that those children with the L-DRD4 polymorphism who received higher quality parenting were reported to have the least sensation-seeking behavior of all the groups. Furthermore, children who did not possess the $L-D R D 4$ polymorphism were unaffected by parenting, which potentially provides support for the differential susceptibility hypothesis discussed above. Although the results of this study do not differentiate between the specific aspects of parenting that were most critical for this relationship, due to the broad measure of "parenting quality" and because the parenting rating scales were so highly correlated, it does provide further evidence that parenting matters. These results are also in line with previous findings linking dopamine genes to sensation-seeking or risk-taking behaviors.

Finally, in a study of effortful control as an indicator of selfregulation, Kochanska, Philibert, and Barry (2009) found that children's attachment security moderated the effect of the risk allele of 5-HTTLPR (short/short or short/long) on a child's ability to self-regulate. Diminished self-regulatory capacity was observed from age 2 to 4.5 but only for children with the risk allele who were insecurely attached to their mothers at the end of the first year. This effect was absent for securely attached children; thus, attachment security appears to act as a buffer against risk conferred by genotype. Attachment security may enhance effective emotional arousal modulation in children who are genetically less well equipped to handle this task (Herrmann et al., 2007; Hofer, 1987). Children with low-risk genotypes may have more effective physiological regulation, and caregiver support may be less important.

Support for the latter argument is found in a study of the dopamine receptor D2 gene (DRD2) on infant physiological responses to stress over the first year of life in relation to infants' experiences with caregivers (Propper et al., 2008). At 3 and 6 months of age, infants with the taq 1 A1 polymorphism of the DRD2 gene (risk), associated with impulse control problems and sensation-seeking behaviors, did not exhibit expected physiological regulation during an ageappropriate stressful situation (i.e., separation from mother) as measured by vagal reactivity (i.e., decrease in respiratory sinus arrhythmia [RSA]). However, results revealed that maternal caregiving behavior moderated the change in RSA response to stress by 12 months of age. Those infants possessing the taq1 A1 polymorphism of DRD2 who were also exposed to sensitive maternal caregiving over the first year of life exhibited a more optimal and expected RSA response to stress at 12 months of age, comparable to the RSA reactivity of those infants possessing the nonrisk version of the gene. 
Infants without the risk allele displayed typical and effective RSA response to stress whether or not mothers were sensitive, suggesting that the caregiving environment may actually be less important for their regulatory outcomes.

\section{Implications of $G \times$ E for developmental psychopathology}

Over the past decade, there has been growing interest in predicting childhood psychopathology using $\mathrm{G} \times \mathrm{E}$ models. Although some studies have looked at genetic effects within the context of more extreme examples of poor parenting, such as maltreatment (Caspi et al., 2002) or physical discipline (Edwards et al., 2010), as predictors of aggression, antisocial behavior, and delinquency, others have looked at family and caregiving factors within the normal range. Here we highlight some of the work focusing on predictors of externalizing symptoms and disorders. For example, Waldman (2007) found that children without $D R D 2$ risk (A1 allele) were no more likely to receive an attention-deficit/hyperactivity disorder (ADHD) diagnosis when mothers had never married or married more than once than were children whose mothers had married only once, but for children carrying the A1 allele (risk) the likelihood of ADHD increased significantly when mothers never married or married more than once. These familial factors presumably affect the caregiving environment, although they were not directly measured.

In contrast, recent research has concentrated on disentangling the specific effects of different types of parenting behaviors in conjunction with child genes. For example, Li and Lee (2012) examined both negative and positive parenting behavior, which have been found to be distinct measures of parenting rather than opposite ends of a single continuum (Ellis \& Nigg, 2009; Pettit, Bates, \& Dodge, 1997) to predict ADHD. They found that the MAOA genotype interacted with negative parenting, but not positive parenting, to predict ADHD symptoms in 6- to 9-year-old boys. Boys homozygous for high activity $M A O A$ demonstrated significantly higher parent- and teacherrated symptoms of inattention as negative parenting behavior increased, relative to boys with the low-activity MAOA genotype. These results provide evidence for the specific influence of negative parenting on the development of ADHD, particularly for boys with high-activity MAOA. In similar findings, Propper, Willoughby, Halpern, Carbone, and Cox (2007) also examined the separate contribution of both sensitive and negative maternal behavior, and results confirmed that these two styles of parenting have differential effects on the development of externalizing behavior (as measured by maternal report) in 30-month-old children. High warm-responsive parenting was associated with decreased externalizing behavior for African American children possessing the short polymorphism of the DRD4 gene. No interactions were found with negative parenting. Another study found that harsh and intrusive maternal parenting, but not sensitive, interacted with the risk (methionine) allele of the brain-derived neurotrophic factor gene to predict oppositional defiant disorder and callous-unemotional behaviors in 3-year-olds (Willoughby, Mills-Koonce,
Propper, \& Waschbusch, 2013). Moreover, harsh-intrusive behaviors in infancy predicted callous-unemotional behaviors, whereas oppositional defiant disorder behaviors were predicted by this behavior in infant and toddlerhood/preschool years. These studies emphasize the importance of carefully measuring caregiving behaviors and exploring distinct characteristics of parenting rather than one broad measure.

This body of work is continuously expanding, but several other investigations have found similar interactions between parenting and multiple candidate genes: the high activity $M A O A$ genotype prospectively predicted conduct disorder, substance use disorder, and ADHD only in youth exposed to less positive parenting (Vanyukov et al., 2007); the interaction of the $L-D R D 4$ polymorphism and insensitive maternal caregiving during infancy predicted increased externalizing behaviors, including oppositional and aggressive behaviors, in preschool-age children (Bakermans-Kranenburg \& van IJzendoorn, 2006); and negative parenting positively predicted conduct disorder in young children, but only among those with the 9/9 genotype of the dopamine active transporter 1 (DAT1) gene (Lahey et al., 2011).

That genes initiate pathways to behavioral adaptation that may be altered by caregiving experiences is supported by a growing literature. Nevertheless, challenges remain in instantiating a model of the etiology of psychopathology that points to the biological processes that may be genetically influenced and that play a role in the emergence of patterns of behavior that constitute impaired mental health and functioning. In the next section, we review literature that addresses the underlying biological processes that are candidates for mediation in pathways to psychopathology.

\section{Physiological Mediators of Parenting and Child Functioning}

Clearly, it is not believed that parenting experiences and genes interact to directly alter children's development; rather, these coactions are mediated through numerous biological mechanisms that are implicated in behavioral adaptations. In human populations, much of this work has focused on regulatory functioning, with specific emphases on peripheral systems associated with arousal and regulation such as the hypothalamic-pituitary-adrenal (HPA) axis and the autonomic nervous system (ANS). Animal models offer evidence for caregiver effects on the development and functioning of the central nervous system, and advances in human neuroscience research have provided opportunities to begin to examine associations between caregiving experiences and neuroanatomical structure and function in early development. Recent human research has begun to parallel an extant animal literature on the associations between early caregiving and the biobehavioral systems that support affiliation and bonding, including the roles of neuropeptides oxytocin and vasopressin in the development of early parent-child relationships. However, for our purposes we will focus on the functioning of the HPA axis and the ANS, given that these systems 
have received the most attention by human researchers with respect to their associations with both early caregiving environments and subsequent child adjustment and maladjustment.

\section{Parenting behaviors and early biopsychosocial models of reactivity and regulation}

Reactivity to environmental stimuli in young children has both genetic and developmental origins. For example, individual differences in early reactivity appear very early in infancy and are thought to be biologically based and have relative stability over time, although evidence suggests that they are modifiable by developmental processes and environmental experiences (Rothbart et al., 2000), particularly variations in caregiving experiences (Rothbart \& Bates, 2006; see also Belsky, Fish, \& Isabella, 1991; Calkins \& Fox, 1992; Engfer, 1993; Matheny, 1986). In contrast, the development of self-regulation is quite protracted, with foundations for adaptive self-regulation emerging in infancy and effortful and autonomous regulation emerging in later childhood (Beauregard, Levesque, \& Paquette, 2004; Calkins, 2011). During the early phases of development, however, there is almost an exclusive reliance on the caregiver by the child to provide emotional scaffolding and external sources of regulation and control needed to help the child modulate arousal. These processes, and their relevance for other normative and pathological child outcomes, have been evidenced by multiple studies of the precursors and sequelae of early psychophysiological reactivity and regulation. In integrating the findings on this topic, Boyce and Ellis (2005) proposed a theoretical framework suggesting that hyperreactivity in stress responsive systems may occur in response to highly stressful early environments, specifically those that are threatening, unpredictable, and lacking in caregiver support. When such conditions are persistent over time, the chronic and prolonged activation of these systems (sometimes referred to as allostatic load) results in an impeded ability of the child to flexibly respond to different levels and types of challenge (McEwen, 1998, 2000) that may have long-term consequences for both mental and physical health during later childhood and adulthood (Evans, 2003, 2004; Gordis, Granger, Susman, \& Trickett, 2008; McEwen \& Seeman, 1999). Here we will focus explicitly on parenting associations with the HPA axis and ANS, as well as the implications of variations in these systems for subsequent child development.

Parenting experiences and early HPA functioning. Research on the end product of HPA activity, the glucocorticoid hormone cortisol, suggests that atypical levels of resting cortisol or cortisol reactivity in response to threat or challenge is associated with deficits in effortful control (Lengua, 2012) and higher levels of externalizing and internalizing behavior problems (Granger, Stansbury, \& Henker, 1994; Granger, Weisz, McCracken, Ikeda, \& Douglas, 1996). Whereas the ideal relation between cortisol response to moderate stress and child competence is often considered to be an inverted $\mathrm{U}$ shape with moderate levels of cortisol response associated with attention, effortful appraisal, and engagement with the environment (Blair et al., 2008), very high or very low levels of cortisol reactivity have been associated with regulatory deficits (de Kloet \& Oitzl, 2003; de Kloet, Oitzl, \& Joels, 1999; Erickson, Drevets, \& Schulkin, 2003). These patterns of cortisol function appear to be consolidated early in development (although they remain highly plastic) and the effects of experience on the development of the HPA responses to stress are well established (Gunnar \& Quevedo, 2008; Meaney \& Szyf, 2005). Animal models (as well as a growing literature based on human studies) clearly implicate early caregiving as a primary influence on the development of the HPA axis (Champagne et al., 2008; Liu, Diorio, Day, Francis, \& Meaney, 2000) through the provision of nurturing supportive environments that appropriately scaffold learning experiences to support well-regulated physiological responses to stress (Gunnar \& Quevedo, 2007; Sroufe, 1996).

To date, several studies have documented correlations between early maternal (Albers, Riksen-Walraven, Sweep, \& de Weerth, 2008; Blair et al., 2008; Pendry \& Adam, 2007) and paternal (Mills-Koonce et al., 2011) caregiving and HPA functioning in young children. Furthermore, Blair et al. (2011) provides evidence for the role of parenting behavior as a mediator of the potentially adverse effects of poverty on early HPA dysfunction based on data collected by the Family Life Project, a large epidemiological study of children and families living in poor, rural communities in the United States. In this recent research, sensitive parenting (defined as warm, engaged, and emotionally supportive caregiving) mediated the association between income-to-needs ratios and baseline measures of child cortisol at 7, 15, and 24 months of age. Perhaps the most convincing evidence, however, comes from experimental manipulation of parenting behaviors through a randomized clinical trial that resulted in both improved parenting and parent-child relationships as well as more optimal HPA functioning in young children (Bakermans-Kranenburg, van IJzendoorn, Pijlman, Mesman, \& Juffer, 2008).

In addition to the potential direct effects of early parenting on children's HPA functioning, there is also evidence that the quality of the early parent-child attachment relationship is also associated with early HPA functioning. The attachment behavioral system includes those infant behaviors that are activated by stress with the goal of reinstating a sense of security, usually best achieved in infancy by close physical contact or proximity with a familiar caregiver (Bowlby, 1969). Under typical conditions, a well-functioning attachment relationship will serve to buffer the infant (and adult) against extreme levels of fearful arousal. When the infant's caregiving history precludes the ability to use the parent as a source of security and external regulation (as is often the case among children with insecure or disorganized attachments; Main, 1990), then the child's cortisol response to stress or challenge is likely to diverge from typical patterns of age- and experience-appropriate reactivity and regulation. To this effect, 
Spangler and Grossmann (1993) reported that children with insecure-disorganized attachment relationships maintained significantly elevated cortisol levels $30 \mathrm{~min}$ after experiencing an emotional challenge as compared to infants with secure strategies; whereas, cortisol levels of infants with insecure-avoidant attachments were intermediate in value. Similar findings have been reported by Hertsgaard, Gunnar, Erickson, and Nachmias (1995) and Bernard and Dozier (2010) and suggest that in infancy dysregulated cortisol activity can occur when adequate child-behavioral strategies cannot be applied, such as the inability to effectively utilize the parent as a source of security and external regulation.

On the extreme end of the parenting spectrum, research identifies early and prolonged experience of abuse, maltreatment, and neglect as highly significant risk factors for atypical behavioral and psychobiological outcomes (Hussey et al., 2005; Kohl, Jonson-Reid, \& Drake, 2009). Although there are exceptions (e.g., King, Mandansky, King, Fletcher, \& Brewer, 2001), several studies have shown that children and adolescents exposed to severe child abuse and neglect or other types of severe trauma have higher levels of baseline cortisol than do comparison children (Carrion, Weems, Ray, \& Reiss, 2002; Cicchetti \& Rogosch, 2001; De Bellis et al., 1999; Delahanty, Nugent, Christopher, \& Walsh, 2005; Pfeffer, Altemus, Heo, \& Jiang, 2007) and hyperactivity of the HPA axis and ANS (Heim, Newport, Mletzko, Miller, \& Nemeroff, 2008).

Although the association between caregiver treatment and child HPA axis hyperreactivity is consistent with Boyce and Ellis' (2005) theoretical framework linking highly stressful early environments to physiological hyperreactivity, emerging theory and research also posits an alternative "attenuation hypothesis" (Gunnar \& Vazquez, 2001; Susman, 2006) whereby the HPA axis adapts to sustained periods of hyperactivity in response to chronic and extreme environments (such as abuse and maltreatment) by downregulating cortisol secretion following a stressor, resulting in hyposecretion. Although several mechanisms have been proposed, such as decreased biosynthesis of hormones in the HPA axis, downregulation of pituitary receptors, and increased negative feedback sensitivity (Fries, Hesse, Hellhammer, \& Hellhammer, 2005; Heim et al., 2000), hyposecretion is proposed to have an adaptive function, as prolonged exposure to cortisol has deleterious effects on brain structures, such as the hippocampus and frontal cortex, as well as cardiovascular and immunological functioning (Bremner \& Vermetten, 2001; De Bellis \& Kuchibhatla, 2006; McEwen \& Wingfield, 2003; Raison \& Miller, 2003; Sapolsky, Romero, \& Munck, 2000). Furthermore, studies of adults retrospectively reporting childhood abuse have reported lower levels of cortisol during the course of the day (Bremner et al., 2003) and in response to hormonal or physical challenge (Heim, Newport, Bonsall, Miller, \& Nemeroff, 2001; Santa Ana et al., 2006). These associations, however, do appear malleable to proper intervention following reports of abuse. For example, a recent study reported that family-based preventative intervention for children at high risk for abuse can alter HPA axis stress responses (Brotman, Goldern, \& Wittstein, 2007) and can alter the daily rhythms of cortisol (Fisher, Stoolmiller, Gunnar, \& Burraston, 2007), potentially reducing the risk for later regulatory and psychopathological disorders.

Parenting behavior and early autonomic functioning. The human nervous system is divided into the central and peripheral nervous systems, and the peripheral nervous system can itself be divided by volition into somatic and autonomic components. The ANS can in turn be further divided into two branches: the parasympathetic nervous system (PNS) and the sympathetic nervous system (SNS). The activity of the PNS is most often indexed by vagal tone, or the neural control of the heart via the vagus nerve. Effective vagal functioning has been related to the ability to maintain homeostasis in the face of situational change by allowing attention to shift from internal processes to external demands, facilitating the use of coping strategies to regulate affective or behavioral arousal (Porges, 1992). Overall, findings support the hypothesis that higher levels of baseline vagal tone and greater vagal withdrawal during a challenge context reflect more effective regulation (Bazhenova, Plonskaia, \& Porges, 2001; Moore \& Calkins, 2004), including higher soothability (Huffman et al., 1998), more attentional control (Huffman et al., 1998; Suess, Porges, \& Plude, 1994), and better emotion regulation (Calkins, 1997; Porges, Doussard-Roosevelt, Portales, \& Greenspan, 1996). In contrast to the PNS, the SNS is associated with the "fight or flight" response to stress (Cannon, 1929) with sympathetic activation freeing and directing metabolic resources to support active defense behaviors. Early attempts to measure SNS activity focused largely on changes in heart rate, although more recently, Nater and Rohleder (2009) have advocated assaying saliva for the enzyme $\alpha$-amylase (sAA), as well as measuring the heart's preejection period (Sherwood, 1995), as an index of sympathetic activity that strongly correlates with other measures of sympathetic activation (Bauer, Quas, \& Boyce, 2002).

As with the HPA axis, the quality of the early caregiving environment likely influences the trajectories of autonomic development from infancy onward (Calkins, Smith, Gill, \& Johnson, 1998; Calkins \& Fox, 1992; Fox, 1989), as regulatory strategies shift from caregiver-child coregulation to internalized and effortful regulation by the infant. Moore and Calkins (2004) found that 3-month-old infants of dyads exhibiting lower synchrony (i.e., the degree to which parents and infants synchronously changed affective displays) showed an atypical response to a social challenge task, exhibiting greater levels of vagal withdrawal during an episode in which they played normally with their mothers and less vagal withdrawal during a situation meant to elicit distress. Working with 6-month-old infants, Porter (2003) demonstrated that children who spent more time in joint communicative sequences with their mothers had higher basal vagal tones than did children in dyads that spent less time engaged in this form of dyadic regulation. From 12 to 18 months, children classified as insecurely attached to their primary caregiver (specifically 
children with insecure-avoidant attachments) displayed higher heart rate, increased vagal withdrawal, and higher levels of sAA (a marker of SNS activity) throughout the entire Strange Situation Paradigm than did infants classified as securely attached (Frigerio et al., 2009; Hill-Soderlund et al., 2008). Among toddlers in foster care, Oosterman, De Schipper, Fisher, Dozier, and Schuengel (2010) demonstrated that children in disordered attachment relationships (an aggregate category including children with disorganized-controlling and insecure-other classifications) exhibited increased sympathetic activity (as indexed by preejection period) over the course of a modified Strange Situation Paradigm.

The findings of various studies have consistently demonstrated that maternal sensitivity is associated with effective autonomic regulation in response to challenge and, conversely, that negative, controlling behaviors are related to poor ANS regulation (e.g., Calkins et al., 1998; Calkins, Graziano, Berdan, Keane, \& Degnan, 2008; Conradt \& Ablow, 2010; Ham \& Tronick, 2006; Moore et al., 2009; Propper $\&$ Moore, 2006). As previously discussed, Propper et al. (2008) found that the effects of maternal sensitivity on autonomic regulation can even overcome genetic risk factors, with infants carrying the "risk" allele of the DRD2 gene initially failing to show expected and normative vagal withdrawal during challenge but later demonstrating normative vagal functioning 6 months later when raised by sensitive and supportive mothers. At the opposite end of the maternal behavior spectrum, Kivlighan and Granger (2006) reported that maternal detachment was associated with higher levels of baseline sAA during infancy, suggesting less flexibility in the ANS to respond adequately to challenge.

Just as with the HPA axis, the findings that exposure to family risk and nonoptimal parenting is associated with alterations of autonomic development are consistent with a biological embedding perspective (Hertzman \& Boyce, 2010). In the short term, maintaining a low level of parasympathetic reactivity, possibly by establishing lower basal levels of vagal tone, may be adaptive. According to Boyce and Ellis (2005), high levels of parasympathetic reactivity would be ill suited to an environment in which challenges were frequent and severe. However, what is adaptive in the short term may not remain so. A young child born into an environment rife with sources of proximal risk is likely to continue to be exposed to those risks. If the resources afforded by the PNS are unavailable, then those offered by the SNS will be drawn upon, perhaps more heavily than in a child born to a less stressful environment (as the small number of studies above that assessed sympathetic response to challenge would suggest). Again, as with the HPA system, conventional theories of reactivity (e.g., Nesse \& Young, 2000) assert that such frequent, large, and prolonged sympathetic activation would impose an allostatic load with deleterious effects on the long-term physical and mental health of the child.

Implications for developmental psychopathology. Across multiple longitudinal studies there is accumulating evidence that moderate levels of psychophysiological reactivity to common stressors are associated with more adaptive shortand long-term outcomes and that both patterns of hyperresponsivity and hyporesponsivity in response to early adversity are associated with less adaptive and more problematic developmental outcomes (Obradović \& Boyce, 2009). For example, internalizing behaviors have been associated with higher levels of SNS reactivity (Fowles, Kochanska, \& Murray, 2000; Weems, Zakem, Costa, Cannon, \& Watts, 2005) and higher levels of HPA reactivity (Adam \& Kumari, 2009; Gunnar, Wewerka, Frenn, Long, \& Grigs, 2009; Halligan, Herbert, Goodyer, \& Murray, 2007). Meanwhile, externalizing behaviors have been associated with lower levels of PNS reactivity (Calkins \& Dedmon, 2000; Calkins, Graziano, \& Keane, 2007; Calkins \& Keane, 2004), SNS reactivity (Beauchaine, Gatzke-Kopp, \& Mead, 2007; Crowell et al., 2006; Gatzke-Kopp, Raine, Loeber, Stouthamer-Loeber, \& Steinhauer, 2002) and HPA reactivity (O'Neal et al., 2010, Oosterlaan, Geurts, Knol, \& Sergeant, 2005; Shirtcliff, Granger, Booth, \& Johnson, 2005). These patterns of reactivity have implications for how children appraise and respond to their environments as well as how their environments continue to influence their ongoing development. For example, it is possible that early insensitive and punitive caregiving environments may result in hyporesponsive stress systems over time (Obradović, 2012); compromise the emotional experiences of fear, guilt, and empathy; increase children's insensitivity to punishment; and ultimately increase their propensities for aggressive and antisocial behaviors (Dadds \& Salmon, 2003). Such a model suggests that early family experiences shape how children react physiologically, cognitively, and behaviorally to salient emotional information about themselves and others and that this multilevel cascade may have profound implications for developmental psychopathology well beyond early childhood (Cox, Mills-Koonce, Propper, \& Gariepy, 2010).

In addition, the effects of early parenting behaviors on the development of child psychophysiological reactivity and regulation may alter the child's sensitivity to future environmental experiences (including ongoing experiences with the caregivers). For example, children who are biologically more reactive have been identified as being more susceptible to the negative effects of environmental adversity as well as the positive effects of environmental support as compared to less-reactive children (Ellis, Boyce, Belsky, BakermansKranenburg, \& van IJzendoorn, 2011). Similar to Belsky's differential susceptibility hypotheses, which posits that temperamentally more-reactive children are more susceptible to both positive and negative environmental conditions (Belsky, 2005; Belsky, Bakermans-Kranenburg, \& van IJzendoorn, 2007), Boyce \& Ellis (2005) propose that physiological reactivity can also be conceptualized as a biological indicator of sensitivity to context. Recent research on individual differences in both ANS and HPA axis functioning provides evidence that heightened physiological reactivity is associated with stronger correlations between environmental experiences 
and children's behavioral development (Boyce, Torshein, Currie, \& Zambon, 2006; Cummings, El-Sheikh, Kouros, \& Keller, 2007; Obradović, Bush, Stamperdahl, Adler, \& Boyce, 2010). The developmental implications of this conceptualization of physiological reactivity are quite profound. Given that the possible implications for atypical physiological reactivity are not mutually exclusive, we can view the ANS and HPA systems as providing both (a) a biological means of transmitting early family experience into a developmental endophenotype underlying typical or atypical developmental outcomes and (b) a biological mechanism that constrains or augments the influence of ongoing environmental experiences on the developing child. In other words, psychophysiological reactivity may serve as both a critical mediator and moderator of early experience on later developmental psychopathology.

\section{Challenges and New Directions}

The genetic and psychophysiological work reviewed here makes clear that direct-effects analyses of the role of either genes/biology or environment in emerging psychopathology are neither accurate nor very revealing of developmental process, largely because they do not reflect the complexity of the developmental system. Instead, acknowledging that family and child factors are embedded in a dynamic biopsychosocial context is key to understanding developmental trajectories of child psychopathology. Adoption of a biopsychosocial framework that emphasizes the dynamic and transactional nature of the developmental system is key to generating empirical work that may contribute substantially to our understanding of development across multiple levels of functioning and across the life span. We would argue that the integration of $\mathrm{G} \times \mathrm{E}$ studies with those that focus on underlying physiological processes that may be affected by caregiving and that support adaptive behavior may be the most fruitful approach to articulating the pathways to psychopathology in its various forms. Such investigations are still relatively rare and beset by numerous challenges, which are evident at the level of conceptualization, investigation, and translation. Here we articulate these challenges and suggest new directions for research that may push the field of developmental psychopathology to greater understanding of the role of biology in the multiple pathways to child adjustment.

\section{Identifying the gene(s), defining the environment, and refining the phenotype}

One important reason that a biopsychosocial perspective is a valuable tool in the empirical study of child psychopathology is that such inquiries force scientists to better articulate the elements of the multiple developmental pathways that exist. Much of the research on $\mathrm{G} \times \mathrm{E}$ interactions focuses on broad indicators of both inherited traits and child outcomes and somewhat global indicators of family process. However, in tandem with specifying the mechanisms of genetic transmissions, identifying and defining the behavioral, and observable, elements of a developmental trajectory is critical. This articulation not only is required of the outcome of interest, such as "child adjustment," but also must be done at every level of the analysis.

For example, an important new and critical direction for $\mathrm{G} \times \mathrm{E}$ studies is the need to move beyond the focus on one genetic allele in prediction of complex outcomes and instead to consider multiple genes, as well as their interaction (Gene $\times$ Gene). The failure to do so may account for some of the mixed results regarding the effects of one specific gene on behavior; examining multiple polymorphisms in combination as haplotypes may ameliorate this issue. Haplotypes refer to a group of alleles on a single chromosome that are usually inherited together. It is likely that these polymorphisms interact, and it is necessary to be aware of these allelic combinations when making inferences about functional and phenotypic associations. For example, Sulik et al. (2012) found that certain outcomes are revealed only when specific allelic combinations as haplotypes are examined. In this work, the interaction between three solute carrier family C6, member 4 gene haplotypes and parenting behavior was a significant predictor of noncompliance from 18 to 54 months age, such that at younger ages one group of children (L10-L12 haplotypes) were more susceptible to parenting than were the others (S10 and S12 haplotypes). However, over time the S10 haplotype group became increasingly affected by parenting, while the S12 group remained relatively unaffected by parenting across the entire study. Not only do these findings highlight the importance of taking into account haplotypes rather than individual genes, but the work's longitudinal design also provides the chance to examine change over time. Many of these findings would not have been clear if they were assessed cross-sectionally, as the effect of parenting for each group was most salient at various points over early development.

Another challenge to specificity in developmental pathways is the articulation and measurement of environment. For example, although the environment in $\mathrm{G} \times \mathrm{E}$ may be obvious to some researchers, if one wishes to trace developmental pathways from genes to behavioral outcomes with any degree of emphasis on the actual process, whether biological or behavioral, better articulation of the relevant features of environment are necessary. Often, researchers assume that environment must mean parenting behavior or other dimensions of the family environment. Such an assumption may be intuitively appealing, and in some cases correct, but it should not preclude looking at other elements of the environment. This focus on family functioning and parenting behavior requires elaboration. Although considerable research has sought to understand the relations between parental behavior and a range of child developmental outcomes, much of this work has been conducted at a very broad level of analysis, using global constructs like attachment, warmth, and monitoring. Analyses of $\mathrm{G} \times \mathrm{E}$ interactions reveal the need for models of family functioning that offer greater specificity regarding proximal processes that may be implicated in the effects of these relationships on children's biological and behavioral functioning (Corter \& Fleming, 1995). 
Phenotypic specificity at the level of outcome is needed as well. Much of the work examining child adjustment has focused on broad indicators of the child's functioning, such as externalizing and internalizing symptoms. Predicting to such indicators is less than satisfying because they are not very revealing of the specific ways in which children's behavior or biology is being influenced or altered by the $G \times$ E interplay. Moreover, many of the measures of child outcome that are used would best be described as general indicators of child functioning, given that individual scales reflecting particular clusters of symptoms are often correlated (e.g., internalizing and externalizing) and given that parents are typically the reporters of the child's functioning. To the extent that investigations can specify and observe particular behaviors or traits in a more nuanced way, identifying linkages to neural or physiological processes that are genetically influenced will be made easier, as will hypothesizing how environmental factors might alter the pathway to the behavioral phenotype.

\section{Situating parenting behaviors and biopsychosocial development in context and culture}

When examining the role of parenting behaviors in the development of early biopsychosocial processes that may increase or decrease the likelihood of later psychopathology in children, it is necessary to consider the contexts and cultures surrounding these family dynamics and developmental processes. Unlike the highly controlled laboratory conditions present for most animal research models, human development does not occur in such a vacuum, and as a result, we must be sensitive to ecological and sociocultural influences on both the parent and child. For example, despite multiple observational studies reporting higher levels of controlling maternal behaviors among African American parents as compared to European American parents (Ispa et al., 2004; MillsKoonce et al., 2011), the positive associations between controlling parenting behaviors and maladaptive behavioral outcomes tend to be smaller among African American families as compared to European American families (Ispa et al., 2004). Some social scientists have interpreted these findings as reflective of cultural differences in how parents view the roles of parenting in children's development. In this example, it is possible that African American parents endorse greater authoritarian parenting beliefs and practices (characterized by higher levels of parental control) as a best practice for child rearing due to a more non-Western, collectivistic cultural heritage as compared to European American parents (DeaterDeckard \& Dodge, 1997; Ispa et al., 2004). There may also be a decoupling of parental control and parental warmth among African American parents (in which the negative correlation between control and warmth is weaker) as compared to European American parents, which may allow for a greater probability of parental warmth to attenuate negative associations between parental control and child outcomes in African American families (Deater-Deckard \& Dodge, 1997).
However, note that these variations in family processes and child outcomes as a function of culture might also be constrained by context or by developmental timing. For example, most of the weak associations between parental control and negative child outcomes for African American families are based on samples of preadolescent and older children. Within the infancy and toddler periods, Clincy, Mills-Koonce, and the Family Life Project Key Investigators (in press) report that increasing levels of intrusiveness and control among African American mothers during the first three years of life are associated with lower levels of language ability, cognitive development, and effortful control and higher levels of peer problems in toddlerhood. Blair et al. (2011) found higher levels of resting cortisol among African American children at 6,15 , and 24 months of age, and this group difference was mediated by observed parenting behaviors. The implications of these findings for subsequent variation in child maladaptation are as of yet unknown. Whereas the basic processes linking parenting behaviors and early biopsychosocial development may be more etic and common across cultures, how these associations ultimately coalesce into child adaptation or maladaptation over time may be more relativistic depending on (a) how the child interprets and internalizes those family processes over time and (b) how developmental variation in biopsychosocial functioning translates to context-specific functioning for that individual.

\section{Using longitudinal models of biopsychosocial development to understand consolidation and maintenance}

It is likely that characteristics of children that are labeled as "stable" or "unstable" at any given point in time can also, and perhaps more appropriately, be described as under developmental consolidation or maintenance over time (Cairns \& Rodkin, 1998). Often, constructs measured in older children that are particularly stable over time are considered trait or traitlike and possibly genetically mediated and resistant to developmental change or modification through intervention. However, examining these phenomena solely during later periods of development may obscure the effects of early developmental processes that contribute to the consolidation of such stable phenotypes over time and, in so doing, both limit our abilities to (a) observe developmentally sensitive critical periods for early intervention to offset later maladaptation and (b) better identify environmental factors contributing to the maintenance of child maladaptation over time.

For example, punishment insensitivity is a characteristic often reported for children with particularly high levels of conduct problems, callous-unemotional traits, and early antisocial behaviors (Dadds \& Salmon, 2003). For children who are less sensitive to punishment, traditional methods of behavior modification to limit aggressive behaviors have proven to have minimal effects and real-world experiences of punishment (such as being hurt during a fight) do not alter patterns of future behavior. Whereas some researchers would charac- 
terize punishment insensitivity as a genetically mediated endophenotype that underlies aggressive and antisocial behavior in children with high levels of conduct problems and callousunemotional traits, Dadds suggests that this characteristic of older children has developmental roots in inconsistent and coercive parenting practices experienced at younger ages, which may alter the neurologically mediated reward-processing and fear-processing systems in children. Recent research has identified parenting experiences in the first year of life as particularly relevant for children genetically susceptible to early-onset conduct problems and callous-unemotional traits (Willoughby et al., 2013). These findings collectively suggest that biopsychosocial processes associated with later pathology may not only begin to consolidate in infancy but may also have highly sensitive, if not critical, developmental periods during the first years of life in some cases. These findings highlight the importance of a biopsychosocial model of development for identifying the predictors, mechanisms, and timing of processes related to the consolidation and maintenance endophenotypic characteristics of children across development and their roles in developmental psychopathology.

\section{Developing genetically informed prevention/intervention}

A clearer understanding of the relations between genes and environments, and identification of the specific child genotypes and caregiving behaviors most important for developing behaviors and pathology, may lead to important improvements in psychosocial interventions and preventions aimed at enriching the child's environment by shaping parenting behavior. Identification of the biological or physiological profiles that may be most receptive to specific behavioral therapies and treatments will allow for more specificity and focused efforts. There are a number of correlational findings in the literature (many of which are described above) that implicate specific candidate genes or moderating pathways that could be relevant for this work. Examining these associations within an experimental framework may allow for a more precise understanding of the effects of interventions that perhaps appeared to be unsuccessful in the past.

Several studies have begun to incorporate molecular genetics into psychosocial intervention/prevention work and provide evidence that this movement away from correlational studies and toward experimental designs may be an exciting and critical next direction in the field. For example, in the first study of its kind, Bakermans-Kranenburg et al. (2008) found that a video feedback intervention promoting positive parenting and sensitive discipline was most effective at decreasing externalizing behavior (at 1-year follow-up) in 1- to 3-yearold children who possessed the risk allele of DRD4

\section{References}

Adam, E. K., \& Kumari, M. (2009). Assessing salivary cortisol in largescale, epidemiological research. Psychoneuroendocrinology, 34, 14231436.
( $L-D R D 4)$ and that the effects were largest for those whose parents showed the most significant increase in use of positive discipline. A recent pilot study (van den Hoofdakker et al., 2012) used this approach to investigate a behavioral parent training aimed to improve ADHD outcomes (which is crucial due to the high variability found in success of such trainings). Findings revealed that children's DAT1 genotype moderated their response to behavioral parent training such that children with two DAT1 10-repeat alleles did not benefit from behavioral parent training beyond their routine clinical care; however, those children with zero or one DATI 10-repeat allele exhibited improvements from behavioral parent training above and beyond their routine clinical care alone.

The implications of this work are far reaching. It may be that specific genes found to be stronger in the presence of environmental risk may guide research on their expression, perhaps leading to genetic diagnoses and improved pharmacological interventions (Evans \& Relling, 1999). Alternatively, if specific environmental effects are found to be stronger in the presence of genetic risk, it could lead to new directions for environmental prevention efforts and help to identify which children will benefit from specific prevention programs and treatments the most.

\section{Conclusions}

Most recent models of genetic influences on both parenting and child behavioral outcomes have discarded any notion that such influences are ever independent of the environment (Meaney, 2010). Behavioral researchers are also beginning to appreciate the converse: Any examination of the family's influence on child functioning must, of necessity, acknowledge that such effects occur in the context of a host of biological processes, whether measured or not (cf. Booth, McHale, \& Lansdale, 2011). In this paper, we have argued that adopting a biopsychosocial approach will enhance an understanding of the pathways between parenting and child psychopathology. We review research that addresses the way in which genes and parenting interact to produce differential outcomes, and we address the underlying physiological processes of child behavior that may be altered by different patterns of parenting behavior. We argue in favor of a more integrated perspective of parenting effects that acknowledges the genetic component to complex behavior but note that we must address the critical biological mediators that are at the heart of developmental process in $\mathrm{G} \times \mathrm{E}$ research. Finally, we highlight areas of challenge and opportunity for this kind of research that will yield greater specificity and offer points of entry for intervention and prevention.

Albers, E. M., Riksen-Walraven, J. M., Sweep, F. C. G. J., \& deWeerth, C. (2008). Maternal behavior predicts infant cortisol recovery from a mild everyday stressor. Journal of Child Psychology and Psychiatry, 49, 97-103. 
Bakermans-Kranenburg, M. J., \& van IJzendoorn, M. H. (2006). Gene environment interaction of the dopamine D4 receptor (DRD4) and observed maternal insensitivity predicting externalizing behavior in preschoolers. Developmental Psychobiology, 48, 406-409.

Bakermans-Kranenburg, M. J., van IJzendoorn, M. H., Pijlman, F. T. A., Mesman, J., \& Juffer, F. (2008). Experimental evidence for differential susceptibility: Dopamine D4 receptor polymorphism (DRD4 VNTR) moderates intervention effects on toddlers' externalizing behavior in a randomized controlled trial. Developmental Psychology, 44, 293-300.

Barr, C. S., Newman, T. K., Shannon, C., Parker, C., Dvoskin, R. L., Becker, M. L., et al. (2004). Rearing condition and rh5-HTTLPR interact to influence limbic-hypothalamic-pituitary-adrenal axis response to stress in infant macaques. Biological Psychiatry, 55, 733-738.

Bates, J. E., Petit, G. S., Dodge, K. A., \& Ridge, B. (1998). Interaction of temperamental resistance to control and restrictive parenting on the development of externalizing behavior. Developmental Psychology, 34, 982-995.

Bauer, A. M, Quas, J. A., \& Boyce, W. T. (2002). Associations between physiological reactivity and children's behavior: Advantages of a multisystem approach. Journal of Developmental and Behavioral Pediatrics, 23,102

Bazhenova, O. V., Plonskaia, O., \& Porges, S. W. (2001). Vagal reactivity and affective adjustment in infants during interaction challenges. Child Development, 72, 1314-1326.

Beauchaine, T. P., Gatzke-Kopp, L., \& Mead, H. K. (2007). Polyvagal theory and developmental psychopathology: Emotion dysregulation and conduct problems from preschool to adolescence. Biological Psychology, 74, 174-184.

Beauregard, M., Levesque, J., \& Paquette, V. (2004). Neural basis of conscious and voluntary self-regulation of emotion. In M. Beauregard (Ed.), Consciousness, emotional self-regulation and the brain (pp. 163-194). Philadelphia, PA: John Benjamins.

Belsky, J. (2005). Differential susceptibility to rearing influence: An evolutionary hypothesis and some evidence. In B. Ellis \& D. Bjorklund (Eds.), Origins of the social mind: Evolutionary psychology and child development (pp. 139-163). New York: Guilford Press.

Belsky, J., Bakermans-Kranenburg, M. J., \& van IJzendoorn, M. H. (2007). For better and for worse: Differential susceptibility to environmental influences. Current Directions in Psychological Science, 16, 300-304.

Belsky, J., Fish, M., \& Isabella, R. A. (1991). Continuity and discontinuity in infant negative and positive emotionality: Family antecedents and attachment consequences. Developmental Psychology, 27, 421-431.

Bennett, A. J., Lesch, K. P., Heils, A., Long, J. C., Lorenz, J. G., Shoaf, S. E., et al. (2002). Early experience and serotonin transporter gene variation interact to influence primate CNS function. Molecular Psychiatry 7, 118-122.

Bernard, K., \& Dozier, M. (2010). Examining infants' cortisol responses to laboratory tasks among children varying in attachment disorganization: Stress reactivity or return to baseline? Developmental Psychology, 46, 1771-1778.

Blair, C., Granger, D. A., Kivlighan, K. T., Mills-Koonce, R., Willoughby, M., Greenberg, M. T., et al. (2008). Maternal and child contributions to cortisol response to emotional arousal in young children from low-income, rural communities. Developmental Psychology, 44, 1095-1109.

Blair, C., Granger, D. A., Willoughby, M., Mills-Koonce, W. R., Cox, M. J., Greenberg, M. T., et al. (2011). Salivary cortisol mediates effects of poverty and parenting on executive functions in early childhood. Child Development, 82, 1970-1984.

Booth, A., McHale, S., \& Lansdale, N. (Eds.). (2011). Biosocial research contributions to understanding family processes and problems. New York: Springer.

Bowlby, J. (1969). Attachment and loss: Vol. 1. Attachment. London: Hogarth Press.

Boyce, W. T., \& Ellis, B. J. (2005). Biological sensitivity to context: I. An evolutionary-developmental theory of the origins and functions of stress reactivity. Development and Psychopathology, 17, 271-301.

Boyce, W., Torsheim, T., Currie, C., \& Zambon, A. (2006). The family affluence scale as a measure of national wealth: Validation of an adolescent self-report measure. Social Indicators Research, 78, 473-487.

Bremner, J. D., \& Vermetten, E. (2001). Stress and development: Behavioral and biological consequences. Developmental Psychopathology, 13, 473-489.

Bremner, J. D., Vythilingam, M., Vermetten, E., Southwick, S. M., McGlashan, T., Nazeer, A., et al. (2003). MRI and PET study of deficits in hippocampal structure and function in women with childhood sexual abuse and posttraumatic stress disorder. American Journal of Psychiatry, 160, 924-932.
Brotman, D. J., Goldern, S. H., \& Wittstein, I. S. (2007). The cardiovascular toll of stress. Lancet, 370, 1089-1100.

Cairns, R. B., \& Rodkin, P. C. (1998). Phenomena regained: From configurations to pathways. In R. B. Cairns, L. R. Bergman, \& J. Kagan (Eds.), Methods and models for studying the individual (pp. 245-265). Thousand Oaks, CA: Sage.

Calkins, S. D. (1997). Cardiac vagal tone indices of temperamental reactivity and behavioral regulation in young children. Developmental Psychobiology, 31, 125-135.

Calkins, S. D. (2011). Caregiving as co-regulation: Psychobiological processes and child functioning. In A. Booth, S. McHale, \& N. Lansdale (Eds.), Biosocial research contributions to understanding family processes and problems (pp. 49-60). New York: Springer.

Calkins, S. D., \& Dedmon, S. E. (2000). Physiological and behavioral regulation in two-year-old children with aggressive/destructive behavior problems. Journal of Abnormal Child Psychology, 28, 103-118. doi:10.1023/A:1005112912906

Calkins, S. D., \& Fox, N. A. (1992). The relations among infant temperament, security of attachment, and behavioral inhibition at 24 months. Child Development, 63, 1456-1472.

Calkins, S. D., \& Fox, N. A. (2002). Self-regulatory processes in early personality development: A multilevel approach to the study of childhood social withdrawal and aggression. Development and Psychopathology, 14, 477-498. doi:10.1017/S095457940200305X

Calkins, S. D., Graziano, P. A., Berdan, L. E., Keane, S. P., \& Degnan, K. A (2008). Predicting cardiac vagal regulation in early childhood from maternal-child relationship quality during toddlerhood. Developmental Psychobiology, 50, 751-766. doi:10.1002/dev.20344

Calkins, S. D., Graziano, P. A., \& Keane, S. P. (2007). Cardiac vagal regulation differentiates among children at risk for behavior problems. Biolog ical Psychology, 74, 144-153. doi:10.1016/j.biopsycho.2006.09.005

Calkins, S. D., \& Keane, S. P. (2004). Cardiac vagal regulation across the preschool period: Stability, continuity, and implications for childhood adjustment. Developmental Psychobiology 45, 101-112.

Calkins, S. D., Smith, C. L., Gill, K. L., \& Johnson, M. C. (1998). Maternal interactive style across contexts: Relations to emotional, behavioral and physiological regulation during toddlerhood. Social Development, 7, 350-369.

Cannon, W. B. (1929). Bodily changes in pain, hunger, fear and rage. South ern Medical Journal, 22, 870.

Carrion, V. G., Weems, C. F., Ray, R., \& Reiss, A. L. (2002). Toward an empirical definition of pediatric PTSD: The phenomenology of PTSD symptoms in youth. Journal of the American Academy of Child \& Adolescent Psychiatry, 41, 166-173.

Caspi, A., McClay, J., Moffitt, T., Mill, J., Martin, J., Craig, I. W., et al. (2002). Role of genotype in the cycle of violence in maltreated children. Science, 297, 851-854. doi:10.1126/science. 1072290

Caspi, A., Moffitt, T. E., Newman, D. L., \& Silva, P. A. (1996). Behavioral observations at age 3 years predict adult psychiatric disorders. Archives of General Psychiatry, 53, 1033-1039.

Caspi, A., Sugden, K., Moffitt, T. E., Taylor, A., Craig, I. W., Harrington, H., et al. (2003). Influence of life stress on depression: Moderation by a polymorphism in the 5-HTT gene. Science, 301), 386-389. doi:10.1126/ science. 1083968

Champagne, D. L., Bagot, R. C., van Hasselt, F., Ramakers, G., Meaney, M. J., de Kloet, E., et al. (2008). Maternal care and hippocampal plasticity: Evidence for experience-dependent structural plasticity, altered synaptic functioning, and differential responsiveness to glucocorticoids and stress. Journal of Neuroscience, 28, 6037-6045. doi:10.1523/jneurosci. 0526-08.2008

Champoux, M., Bennett, A., Shannon, C., Higley, J. D., Lesch, K. P., \& Suomi, S. J. (2002). Serotonin transporter gene polymorphism, differential early rearing, and behavior in rhesus monkey neonates. Molecular Psychiatry, 7, 1058-1063.

Cicchetti, D. (1984). The emergence of developmental psychopathology. Child Development, 55, 1-7.

Cicchetti, D. (1993). Developmental psychopathology: Reactions, reflections, projections. Developmental Review, 13, 471-502.

Cicchetti, D., \& Dawson, G. (2002). Multiple levels of analysis [Editorial]. Development and Psychopathology, 14, 417-420.

Cicchetti, D., \& Rogosch, F. A. (1996). Equifinality and multifinality in developmental psychopathology. Development and Psychopathology, 8, 597-600.

Cicchetti, D., \& Rogosch, F. A. (2001). Diverse patterns of neuroendocrine activity in maltreated children. Development and Psychopathology, 13, 677-694. 
Cicchetti, D., Rogosch, F. A., \& Thibodeau, E. L. (2012). The effects of child maltreatment on early signs of antisocial behavior: Genetic moderation by tryptophan hydroxylase, serotonin transporter, and monoamine oxidase A genes. Development and Psychopathology, 24, 907-928.

Clincy, A., Mills-Koonce, W. R., \& the Family Life Project Key Investigators. (in press). Trajectories of intrusive parenting during toddlerhood and school adjustment for low-income African American boys. American Journal of Orthopsychiatry.

Conradt, E., \& Ablow, J. (2010). Infant physiological response to the stillface paradigm: Contributions of maternal sensitivity and infants' early regulatory behavior. Infant Behavior and Development, 33, 251-265.

Corter, C., \& Fleming, A. (1995). The psychobiology of maternal behavior in human beings. In M. Bornstein (Ed.). Handbook of parenting: Vol. 2. Biology and ecology of parenting (pp. 141-181). New York: Guilford Press.

Cox, M. J., Mills-Koonce, W. R., Propper, C. B., \& Gariepy, J. L. (2010). Systems theory and cascades in developmental psychopathology. Development and Psychopathology, 22, 497-506.

Crowell, S. E., Beauchaine, T. P., Gatzke-Kopp, L., Sylvers, P., Mead, H., \& Chipman-Chacon, J. (2006). Autonomic correlates of attention-deficit/ hyperactivity disorder and oppositional defiant disorder in preschool children. Journal of Abnormal Psychology, 115, 174-178. doi:10.1037/ 0021-843X.115.1.174

Cummings, E. M., Davies, P. T., \& Campbell, S. B. (2000). Developmental psychopathology and family process: Theory, research and clinical implications. New York: Guilford Press.

Cummings, E., El-Sheikh, C. D., Kouros, C. D., \& Keller, P. S. (2007). Children's skin conductance reactivity as a mechanism of risk in the context of parental depressive symptoms. Journal of Child Psychology and Psychiatry, 48, 436-445. doi:10.1111/j.1469-7610.2006.01713.

Dadds, M. R., \& Salmon, K. (2003). Punishment insensitivity and parenting: Temperament and learning as interacting risks for antisocial behavior. Clinical Child and Family Psychology Review, 6, 69-86.

Davies, P. T., \& Cummings, E. (1998). Exploring children's emotional security as a mediator of the link between marital relations and child adjustment. Child Development, 69, 124-139. doi:10.2307/1132075

Deater-Deckard, K., \& Dodge, K. A. (1997). Spare the rod, spoil the authors: Emerging themes in research on parenting and child development. Psychological Inquiry, 8, 230-235.

De Bellis, M. D., Keshavan, M., Clark, D. B., Casey, B. J., Giedd, J., Boring, A. M., et al. (1999). Developmental traumatology Part II: Brain development. Biological Psychiatry, 45, 1271-1284.

De Bellis, M. D., \& Kuchibhatla, M. (2006). Cerebellar volumes in pediatric maltreatment-related posttraumatic stress disorder. Biological Psychiatry, 60, 697.

de Kloet, E. R., \& Oitzl, M. S. (2003). Who cares for a stressed brain? The mother, the kid or both? Neurobiology of Aging, 24(Suppl. 1), S61S65; discussion S67-S68.

de Kloet, E. R., Oitzl, M. S., \& Joels, M. (1999). Stress and cognition: Are corticosteroids good or bad guys? Trends in Neurosciences, 22, 422-426.

Delahanty, D. L., Nugent, N. R., Christopher, N. C., \& Walsh, M. (2005). Initial urinary epinephrine and cortisol levels predict acute PTSD symptoms in child trauma victims. Psychoneuroendocrinology, 30, $121-128$.

Edwards, A. C., Dodge, K. A., Latendresse, S. J., Lansford, J. E., Bates, J. E., Pettit, G. S., et al. (2010). MAOA-uVNTR and early physical discipline interact to influence delinquent behavior. Journal of Child Psychology and Psychiatry, 51, 679-687. doi:10.1111/j.1469-7610.2009.02196.x

Ellis, B. J., Boyce, W. T., Belsky, J., Bakermans-Kranenburg, M. J., \& van IJzendoorn, M. H. (2011). Differential susceptibility to the environment: An evolutionary-neurodevelopmental theory. Development and Psychopathology, 23, 7-28.

Ellis, B., \& Nigg, J. (2009). Parenting practices and attention-deficit/ hyperactivity disorder: New findings suggest partial specificity of effects. Journal of the American Academy of Child \& Adolescent Psychiatry, 48, 1-9.

Engfer, A. (1993). Antecedents and consequences of shyness in boys and girls: A 6-year longitudinal study. In H. Rubin \& J. B. Asendorpf (Eds.), Social withdrawal, inhibition, and shyness (pp. 49-80). Hillsdale, NJ: Erlbaum.

Enoch, M. A., Steer, C. D., Newman, T. K., Gibson, N. N., \& Goldman, D. D. (2010). Early life stress, MAOA, and gene-environment interactions predict behavioral disinhibition in children. Genes, Brain and Behavior, 9, 65-74. doi:10.1111/j.1601-183X.2009.00535.x

Erath, S. A., El-Sheikh, M., Hinnant, J., \& Cummings, E. (2011). Skin conductance level reactivity moderates the association between harsh parent- ing and growth in child externalizing behavior. Developmental Psychology, 47, 693-706.

Erickson, K., Drevets, W., \& Schulkin, J. (2003). Glucocorticoid regulation of diverse cognitive functions in normal and pathological emotional states. Neuroscience \& Biobehavioral Reviews, 27, 233-246.

Evans, G. W. (2003). A multimethodological analysis of cumulative risk and allostatic load among rural children. Developmental Psychology, 39, 924-933.

Evans, G. W. (2004). The environment of childhood poverty. American Psychologist, 59, 77-92.

Evans, W. E., \& Relling, M. V. (1999). Pharmacogenomics: Translating functional genomics into rational therapeutics. Science, 286, 487-491.

Fisher, P. A., Stoolmiller, M., Gunnar, M. R., \& Burraston, B. O. (2007). Effects of a therapeutic intervention for foster preschoolers on diurnal cortisol activity. Psychoneuroendocrinology, 32, 892-905.

Foley, D. L., Eaves, L. J., Wormley, B., Silberg, J. L., Maes, H. H., Kuhn, J., et al. (2004). Childhood adversity, monoamine oxidase A genotype, and risk for conduct disorder. Archives of General Psychiatry, 61, 738-744. doi:10.1001/archpsyc.61.7.738

Fowles, D. C., Kochanska, G., \& Murray, K. (2000). Electrodermal activity and temperament in preschool children. Psychophysiology, 37, 777-787. doi: $10.1111 / 1469-8986.3760777$

Fox, N. A. (1989). The psychophysiological correlates of emotional reactivity during the first year of life. Developmental Psychology, 25, 364-372.

Fox, N. A., Nichols, K. E., Henderson, H. A., Rubin, K., Schmidt, L., Hamer, D., et al. (2005). Evidence for a gene-environment interaction in predicting behavioral inhibition in middle childhood. Psychological Science, 16, 921-926. doi:10.1111/j.1467-9280.2005.01637.

Frazzetto, G., Di Lorenzo, G., Carola, V., Proietti, L.,Sokolowska, E., Siracusano, A., et al. (2007). Early trauma and increased risk for physical aggression during adulthood: The moderating role of MAOA genotype. PLoS ONE, 2, e486. Retrieved from http://www.journal.pone.0000486

Fries, E., Hesse, J., Hellhammer, J., \& Hellhammer, D. H. (2005). A new view on hypocortisolism. Psychoneuroendocrinology 30, 1010-1016.

Frigerio, A., Ceppi, E., Rusconi, M., Giorda, R., Raggi, M. E., \& Fearon, P. (2009). The role played by the interaction between genetic factors and attachment in the stress response in infancy. Journal of Child Psychology and Psychiatry 50, 1513-1522.

Gatzke-Kopp, L. M., Raine, A., Loeber, R., Stouthamer-Loeber, M., \& Steinhauer, S. R. (2002). Serious delinquent behavior, sensation seeking, and electrodermal arousal. Journal of Abnormal Child Psychology, 30, 477-486.

Gershoff, E. T. (2002). Parental corporal punishment and associated child behaviors and experiences: A meta-analytic and theoretical review. Psychological Bulletin, 128, 539-579.

Goldsmith, H. H., \& Hewitt, E. C. (2003). Validity of parental report of temperament: Distinctions and needed research. Infant Behavior \& Development, 26, 108-111. doi:10.1016/S0163-6383(02)00172-8

Goldsmith, H. H., Lemery, K. S., Buss, K. A., \& Campos, J. J. (1999). Genetic analyses of focal aspects of infant temperament. Developmental Psychology, 35, 972-985. doi:10.1037/0012-1649.35.4.972

Gordis, E. B., Granger, D.A., Susman, E. J., \& Trickett, P. K., (2008). Salivary alpha amylase-cortisol asymmetry in maltreated youth. Hormones and Behavior 53, 96-103.

Gottlieb, G. (1991). Experiential canalization of behavioral development Theory. Developmental Psychology, 27, 4-13.

Gottlieb, G. (2007). Probabilistic epigenesis. Developmental Science, 10, $1-11$.

Granger, D. A., Stansbury, K., \& Henker, B. (1994). Preschoolers' behavioral and neuroendocrine responses to social challenge. Merrill-Palmer Quarterly, 40, 20-41.

Granger, D. A., Weisz, J. R., McCracken, J. M., Ikeda, S. C., \& Douglas, P. (1996). Reciprocal influences among adrenocortical activation, psychosocial processes, and the behavioral adjustment of clinic-referred children. Child Development, 67, 3250-3262.

Gunnar, M., \& Quevedo, K. (2007). The neurobiology of stress and development. Annual Review of Psychology, 58, 145-173.

Gunnar, M. R., \& Quevedo, K. M. (2008). Early care experiences and HPA axis regulation in children: A mechanism for later trauma vulnerability. Progress in Brain Research, 167, 137-149.

Gunnar, M. R., \& Vazquez, D. M. (2001). Low cortisol and a flattening of expected daytime rhythm: Potential indices of risk in human development. Development and Psychopathology, 13, 515.

Gunnar, M. R., Wewerka, S., Frenn, K., Long, J. D., \& Griggs, C. (2009). Developmental changes in hypothalamus-pituitary-adrenal activity over 
the transition to adolescence: Normative changes and association with puberty. Development and Psychopathology, 21, 69-85.

Haberstick, B. C., Lessem, J. M., Hopfer, C. J., Smolen, A., Ehringer, M. A., Timberlake, D., et al. (2005). Monoamine oxidase A (MAOA) and antisocial behaviors in the presence of childhood and adolescent maltreatment. American Journal of Medical Genetics, 135B, 59-64.

Halligan, S. L., Herbert, J., Goodyer, I., \& Murray, L. (2007). Disturbances in morning cortisol secretion in association with maternal postnatal depression predict subsequent depressive symptomatology in adolescents. Biological Psychiatry, 62, 40-46.

Ham, J., \& Tronick, E. Z. (2006). Infant resilience to the stress of the stillface. Annals of the New York Academy of Sciences, 1094, 297-302.

Hariri, A. R., Mattay, V. S., Tessitore, A., Kolachana, B., Fera, F., Goldman, D., et al. (2002). Serotonin transporter genetic variation and the response of the human amygdala. Science, 29, 400-403.

Heim, C., Newport, D. J., Bonsall, R., Miller, A. H., \& Nemeroff, C. B. (2001). Altered pituitary-adrenal axis responses to provocative challenge tests in adult survivors of childhood abuse. American Journal of Psychiatry, $158,575-581$

Heim, C., Newport, D. J., Heit, S., Graham, Y. P., Wilcox, M., Bonsall, R., et al. (2000). Pituitary-adrenal and autonomic responses to stress in women after sexual and physical abuse in childhood. Journal of the American Medical Association, 284, 592-597.

Heim, C., Newport, D. J., Mletzko, T., Miller, A. H., \& Nemeroff, C. B. (2008). The link between childhood trauma and depression: Insights from HPA axis studies in humans. Psychoneuroendocrinology, 33, 693-710.

Herrmann, M. J., Huter, T., Muller, F., Muhlberger, A., Pauli, P., Reif, A., et al. (2007). Additive effects of serotonin transporter and tryptophan hydroxylase-2 gene variation on emotional processing. Cerebral Cortex, $17,1160-1163$

Hertsgaard, L., Gunnar, M., Erickson, M., \& Nachmias, M. (1995). Adrenocortical response to the strange situation in infants with disorganized/disoriented attachment relationships. Child Development, 66, 1100-1106.

Hertzman, C., \& Boyce, T. (2010-03). How experience gets under the skin to create gradients in developmental health. Annual Review of Public Health, 31, 329-347. doi:10.1146/annurev.publhealth.012809.103538

Hill-Soderlund, A. L., Mills-Koonce, W., Propper, C., Calkins, S. D., Granger, D. A., Moore, G. A., et al. (2008). Parasympathetic and sympathetic responses to the strange situation in infants and mothers from avoidant and securely attached dyads. Developmental Psychobiology, 50, 361376. doi:10.1002/dev.20302

Hofer, M. A. (1987). Early social relationships: A psychobiologist's view. Child Development, 58, 633-647.

Horwitz, B. N., \& Neiderhiser, J. M. (2011). Gene-environment interplay, family relationships, and child adjustment. Journal of Marriage and Family, 73, 804-816.

Huffman, L. C., Bryan, Y., del Carmen, R., Pederson, F., Doussard-Roosevelt, J., \& Porges, S. (1998). Infant temperament and cardiac vagal tone: Assessments at twelve weeks of age. Child Development, 69, 624-635.

Huizinga, D., Haberstick, B. C., Smolen, A., Menard, S., Young, S. E., Corley, R. P., et al. (2006). Childhood maltreatment, subsequent antisocial behavior, and the role of monoamine oxidase A genotype. Biological Psychiatry, 60, 677-683. doi:10.1016/j.biopsych.2005.12.022

Hussey, J. M., Marshall, J. M., English, D. J., Knight, E. D., Lau, A. S., Dubowitz, H., et al. (2005). Defining maltreatment according to substantiation: Distinction without a difference? Child Abuse \& Neglect, 29, 479-492.

Ispa, J. M., Fine, M. A., Halgunseth, L. C., Harper, S., Robinson, J., Boyce, L., et al. (2004). Maternal intrusiveness, maternal warmth, and mothertoddler relationship outcomes: Variations across low-income ethnic and acculturation groups. Child Development, 75, 1613-1631.

Johnston, T. D., \& Edwards, L. (2002). Genes, interactions and the development of behavior. Psychological Review, 109, 26-34.

Kim-Cohen, J. J., Caspi, A. A., Taylor, A. A., Williams, B. B., Newcombe, R. R., Craig, I. W., et al. (2006). MAOA, maltreatment, and gene-environment interaction predicting children's mental health: New evidence and a meta-analysis. Molecular Psychiatry, 11, 903-913. doi:10.1038/ sj.mp. 4001851

King, J. A., Mandansky, D., King, S., Fletcher, K., \& Brewer, J. (2001). Early sexual abuse and low cortisol. Psychiatry \& Clinical Neurosciences, 55, $71-74$.

Kivlighan, K. T., \& Granger, D. A. (2006). Salivary $\alpha$-amylase response to competition: Relation to gender, previous experience, and attitudes.
Psychoneuroendocrinology, 31, 703-714. doi:10.1016/j.psyneuen.2006. 01.007

Kochanska, G., Philibert, R. A., \& Barry, R. A. (2009). Interplay of genes and early mother-child relationship in the development of self-regulation from toddler to preschool age. Journal of Child Psychology and Psychiatry, 50, 1331-1338. doi:10.1111/j.1469-7610.2008.02050.x

Kohl, P. L., Jonson-Reid, M., \& Drake, B. (2009). Time to leave substantiation behind: Findings from a national probability study. Child Maltreatment, 14, 17-26.

Lahey, B. B., Rathouz, P. J., Lee, S. S., Chronis-Tuscano, A., Pelham, W. E., Waldman, I. D., et al. (2011). Interactions between early parenting and a polymorphism of the child's dopamine transporter gene in predicting future child conduct disorder symptoms. Journal of Abnormal Psychology, 120, 33-45. doi:10.1037/a0021133

Lengua, L. J. (2012). Poverty, the development of effortful control, and children's academic, social, and emotional adjustment. In V. Maholmes \& R. B. King (Eds.), The Oxford handbook of poverty and child development (pp. 491-511). New York: Oxford University Press.

Li, J. J., \& Lee, S. S. (2012). Association of positive and negative parenting behavior with childhood ADHD: Interactions with offspring monoamine oxidase A (MAO-A) genotype. Journal of Abnormal Child Psychology, 40, 165-175. doi:10.1007/s10802-011-9553-z

Liu, D., Diorio, J., Day, J. C., Francis, D. D., \& Meaney, M. J. (2000). Maternal care, hippocampal synaptogenesis and cognitive development in rats. Nature Neuroscience, 3, 799-806.

Main, M. (1990). Cross-cultural studies of attachment organization: Recent studies, changing methodologies, and the concept of conditional strategies. Human Development, 33, 48-61.

Matheny, A. P. Jr. (1986). Injuries among toddlers: Contributions from child, mother, and family. Journal of Pediatric Psychology, 11, 163-176.

McEwen, B. S. (1998). Protective and damaging effects of stress mediators. New England Journal of Medicine 338, 171-179.

McEwen, B. S. (2000). Effects of adverse experiences for brain structure and function. Biological Psychiatry 48, 721-731.

McEwen, B. S., \& Seeman, T. (1999). Protective and damaging effects of mediators of stress: Elaborating and testing the concepts of allostasis and allostatic load. Annals of the New York Academy of Sciences, 896, 30-47.

McEwen, B. S., \& Wingfield, J. C. (2003). The concept of allostasis in biology and biomedicine. Hormones and Behavior, 43, 2-15.

Meaney, M. (2010). Epigenetics and the biological definition of gene $\mathrm{x}$ environment interactions. Child Development, 81, 49-71.

Meaney, M. J., \& Szyf, M. (2005). Maternal care as a model for experiencedependent chromatin plasticity? Trends in Neuroscience, 28, 456-463.

Meunier, J., Bisceglia, R., \& Jenkins, J. M. (2012). Differential parenting and children's behavioral problems: Curvilinear associations and motherfather combined effects. Developmental Psychology, 48, 987-1002. doi: $10.1037 / \mathrm{a} 0026321$

Michel, G., \& Moore, C. (1995). Developmental psychobiology: An interdis ciplinary science. Cambridge, MA: MIT Press.

Mills-Koonce, W. R., Garrett-Peters, P., Barnett, M., Granger, D., Blair, C., Cox, M. J., et al. (2011). Father contributions to cortisol responses in infancy and early childhood. Developmental Psychology, 47, 388-395. doi:10.1037/a0021066

Moffitt, T. E., Caspi, A., \& Rutter, M. (2006). Measured gene-environment interactions in psychopathology: Concepts, research strategies, and implications for research, intervention, and public understanding of genetics. Perspectives on Psychological Science, 1, 5-27. doi:10.1111/j.1745-6916. 2006.00002.x

Moore, G. A., \& Calkins, S. D. (2004). Infants' vagal regulation in the stillface paradigm is related to dyadic coordination of mother-infant interaction. Developmental Psychology, 40, 1068-1080. doi:10.1037/0012-1649. 40.6.1068

Moore, G. A., Hill-Soderlund, A. L., Propper, C. B., Calkins, S. D., MillsKoonce, W., \& Cox, M. J. (2009). Mother-infant vagal regulation in the face-to-face still-face paradigm is moderated by maternal sensitivity. Child Development, 80, 209-223. doi:10.1111/j.1467-8624.2008. 01255.x

Nater, U. M., \& Rohleder, N. N. (2009). Salivary alpha-amylase as a noninvasive biomarker for the sympathetic nervous system: Current state of research. Psychoneuroendocrinology, 34, 486-496. doi:10.1016/j.psyneuen. 2009.01.014

Nesse, R. M., \& Young, E. A. (2000). The evolutionary origins and functions of the stress response. In G. Fink (Ed.), Encyclopedia of stress (Vol. 2, pp. 79-84). San Diego, CA: Academic Press. 
Obradović, J. (2012). How can the study of physiological reactivity contribute to our understanding of adversity and resilience processes in development? Development and Psychopathology, 24, 371-387. doi:10.1017/ S0954579412000053

Obradović, J., \& Boyce, W. T. (2009). Individual differences in behavioral, physiological, and genetic sensitivities to contexts: Implications for development and adaptation. Developmental Neuroscience, 31, 300-308.

Obradović, J., Bush, N. R., Stamperdahl, J., Adler, N. E., \& Boyce, W. T. (2010). Biological sensitivity to context: The interactive effects of stress reactivity and family adversity on socioemotional behavior and school readiness. Child Development, 81, 270-289. doi:10.1111/j.1467-8624.2009. 01394.x

O'Neal, C. R., Brotman, L., Huang, K., Gouley, K., Kamboukos, D., Calzada, E. J., et al. (2010). Understanding relations among early family environment, cortisol response, and child aggression via a prevention experiment. Child Development, 81, 290-305. doi:10.1111/j.1467-8624. 2009.01395.x

Oosterlaan, J., Geurts, H. M., Knol, D. L., \& Sergeant, J. A. (2005). Low basal salivary cortisol is associated with teacher-reported symptoms of conduct disorder. Psychiatry Research, 134, 1-10. doi:10.1016/j. psychres.2004.12.005

Oosterman, M., De Schipper, J., Fisher, P., Dozier, M., \& Schuengel, C. (2010). Autonomic reactivity in relation to attachment and early adversity among foster children. Development and Psychopathology, 22, 109-118. doi:10.1017/S0954579409990290

Patterson, G. R., Reid, J. B., \& Dishion, T. J. (1992). Antisocial boys. Eugene, OR: Castalia.

Pendry, P., \& Adam, E. K. (2007). Associations between parents' marital functioning, maternal parenting quality, maternal emotion and child cortisol levels. International Journal of Behavioral Development, 31, 218-231.

Pettit, G. S., Bates, J. E., \& Dodge, K. A. (1997). Supportive parenting, ecological context, and children's adjustment: A seven-year longitudinal study. Child Development, 68, 908-923.

Pfeffer, C. R., Altemus, M., Heo, M., \& Jiang, H. (2007). Salivary cortisol and psychopathology in children bereaved by the September 11, 2001, terror attacks. Biological Psychiatry, 61, 957-965.

Porges, S. W. (1992). Autonomic regulation and attention. In B. M. Campbell, H. Hayne, \& R. Richardson (Eds.), Attention and information processing in infants and adults (pp. 201-223). Hillsdale, NJ: Erlbaum.

Porges, S. W., Doussard-Roosevelt, J. A., Portales, A. L., \& Greenspan, S. I. (1996). Infant regulation of the vagal "brake" predicts child behavior problems: A psychobiological model of social behavior. Developmental Psychobiology, 29, 697-712.

Porter, C. L. (2003). Coregulation in mother-infant dyads: Links to infants' cardiac vagal tone. Psychological Reports, 92, 307-319. doi:10.2466/ PR0.92.1.307-319

Posner, M. I., Rothbart, M. K., \& Sheese, B. E. (2007). Attention genes. Developmental Science, 10, 24-29. doi:10.1111/j.1467-7687.2007.00559.x

Propper, C., \& Moore, G. A. (2006). The influence of parenting on infant emotionality: A multi-level psychobiological perspective. Developmental Review, 26, 427-460. doi:10.1016/j.dr.2006.06.003

Propper, C., Moore, G., Mills-Koonce, R., Halpern, C., Hill, A., Calkins, S., et al. (2008). Gene-environment contributions to the development of vagal tone. Child Development, 79, 1378-1395.

Propper, C., Willoughby, M., Halpern, C. T., Carbone, M. A., \& Cox, M. (2007). Parenting quality, DRD4, and the prediction of externalizing and internalizing behaviors in early childhood. Developmental Psychobiology, 49, 619-632.

Raison, C. L., \& Miller, A. H. (2003). When not enough is too much: The role of insufficient glucocorticoid signaling in the pathophysiology of stressrelated disorders. American Journal of Psychiatry, 160, 1554-1565.

Richters, J. E. (1997). The Hubble hypothesis and the developmentalist's dilemma. Development and Psychopathology, 9, 193-229

Rothbart, M. K., Ahadi, S. A., \& Evans, D. E. (2000). Temperament and personality: Origins and outcomes. Journal of Personality and Social Psychology, 78, 122-135.

Rothbart, M. K., \& Bates, J. E. (2006). Temperament. In W. Damon, R. Lerner, \& N. Eisenberg (Eds.), Handbook of child psychology: Social, emotional, and personality development (6th ed., pp. 99-166). Hoboken, NJ: Wiley.

Rothbaum, F., \& Weisz, J. R. (1994). Parental caregiving and child externalizing behavior in nonclinical samples: A meta-analysis. Psychological Bulletin, 116, 55-74.
Rutter, M., \& Sroufe, L. (2000). Developmental psychopathology: Concepts and challenges. Development and Psychopathology, 12, 265-296. doi:10.1017/S0954579400003023

Sadeh, N., Javdani, S., Jackson, J. J., Reynolds, E. K., Potenza, M. N., Gelernter, J., et al. (2010). Serotonin transporter gene associations with psychopathic traits in youth vary as a function of socioeconomic resources. Journal of Abnormal Psychology, 119, 604-609. doi:10.1037/a0019709

Sameroff, A. (2010). A unified theory of development: A dialectic integration of nature and nurture. Child Development, 81, 6-22.

Santa Ana, E. J., Saladin, M. E., Back, S. E., Waldrop, A. E., Spratt, E. G., McRae, A. L., et al. (2006). PTSD and the HPA axis: Differences in response to the cold pressor task among individuals with child vs. adult trauma. Psychoneuroendocrinology, 31, 501-509.

Sapolsky, R. M., Romero, L. M., \& Munck, A. U. (2000). How do glucocorticoids influence stress responses? Integrating permissive, suppressive, stimulatory, and preparative actions. Endocrine Reviews, 21, 55-89.

Sheese, B. E., Voelker, P. M., Rothbart, M. K., \& Posner, M. I. (2007). Parenting quality interacts with genetic variation in dopamine receptor D4 to influence temperament in early childhood. Development and Psychopathology, 19, 1039-1046. doi:10.1017/S0954579407000521

Sherwood, A. (1995). Use of impedance cardiography in cardiovascular reactivity research. In J. Blascovich \& E. S. Katkin (Eds.), Cardiovascular reactivity to psychological stress and disease (pp. 157-199). Washington, DC: American Psychological Association.

Shirtcliff, E. A., Granger, D. A., Booth, A., \& Johnson, D. (2005). Low salivary cortisol and externalizing problem behavior in youth. Development and Psychopathology, 17, 1-18.

Shonkoff, J. (2010). Building a new biodevelopmental framework to guide the future of early childhood policy. Child Development, 81, 49-71, 357-367.

Spangler, G. G., \& Grossmann, K. E. (1993). Biobehavioral organization in securely and insecurely attached infants. Child Development, 64, 14391450.

Sroufe, L. A. (1996). Emotional development: The organization of emotional life in the early years. New York: Cambridge University Press.

Sroufe, L. A., \& Rutter, M. (1984). The domain of developmental psychopathology. Child Development, 55, 17-29.

Suess, P. E., Porges, S. W., \& Plude, D. J. (1994). Cardiac vagal tone and sustained attention in school-age children. Psychophysiology, 31, 17-22.

Sulik, M. J., Eisenberg, N., Lemery-Chalfant, K., Spinrad, T. L., Silva, K. M., Eggum, N. D., et al. (2012). Interactions between serotonin transporter gene haplotypes and quality of mothers' parenting predict the development of children's noncompliance. Developmental Psychology, 48 740-754. doi:10.1037/a0025938

Suomi, S. J. (2004). How gene-environment interactions shape biobehavioral development: Lessons from studies with rhesus monkeys. Research in Human Development, 1, 205-222.

Suomi, S. J. (2005). Genetic and environmental factors influencing the expression of impulsive aggression and serotonergic functioning in rhesus monkeys. In R. E. Tremblay, W. W. Hartup, \& J. Archer (Eds.), Developmental origins of aggression (pp. 63-82). New York: Guilford Press.

Suomi, S. J. (2006). Risk, resilience, and gene $\times$ environment interactions in rhesus monkeys. Annals of the New York Academy of Sciences, $1094,52-62$

Susman, E. J. (2006). Psychobiology of persistent antisocial behavior: Stress, early vulnerabilities and the attenuation hypothesis. Neuroscience Biobehavioral Reviews, 30, 376-389.

Tucker-Drob, E. M., \& Harden, K. (2012). Intellectual interest mediates gene $\times$ socioeconomic status interaction on adolescent academic achievement. Child Development, 83, 743-757.

van den Hoofdakker, B. J., Nauta, M. H., Dijck-Brouwer, D., van der VeenMulders, L., Sytema, S., Emmelkamp, P. G., et al. (2012). Dopamine transporter gene moderates response to behavioral parent training in children with ADHD: A pilot study. Developmental Psychology, 48, 567574.

Vanyukov, M., Maher, B., Devlin, B., Kirillova, G., Kirisci, L., Yu, L., et al. (2007). The MAOA promoter polymorphism, disruptive behavior disorders, and early onset substance use disorder: Gene-environment interaction. Psychiatric Genetics, 17, 323-332.

Waldman, I. D. (2007). Gene-environment interactions reexamined: Does mother's marital stability interact with the dopamine receptor D2 gene in the etiology of childhood attention-deficit/hyperactivity disorder? Development and Psychopathology, 19, 1117-1128. doi:10.1017/ S0954579407000570 
Weems, C. F., Zakem, A., Costa, N. M., Cannon, M. F., \& Watts, S. E. (2005). Physiological response and childhood anxiety: Association with symptoms of anxiety disorders and cognitive bias. Journal of Clinical Child and Adolescent Psychology, 34, 712-723.

Widom, C. S., \& Brzustowicz, L. M. (2006). MAOA and the "cycle of violence": Childhood abuse and neglect, MAOA genotype, and risk for violent and antisocial behavior. Biological Psychiatry, 60, 684-689.

Willoughby, M. T., Mills-Koonce, W. R., Propper, C. B., \& Waschbusch, D. A. (2013). Observed parenting behaviors interact with a polymorphism of the brain-derived neurotrophic factor gene to predict the emer- gence of oppositional-defiant and callous-unemotional behaviors at age 3 years. Development and Psychopathology, 25, 903-917.

Wright, J., Schnupp, R., Beaver, K. M., Delisi, M., \& Vaughn, M. (2012). Genes, maternal negativity, and self-control: Evidence of a gene $\times$ environment interaction. Youth Violence and Juvenile Justice, 10, 245-260. doi: $10.1177 / 1541204011429315$

Young, S. E., Smolen, A., Hewitt, J. K., Haberstick, B. C., Stallings, M. C., Corley, R. P., et al. (2006). Interaction between MAO-A genotype and maltreatment in the risk for conduct disorder: Failure to confirm in adolescent patients. American Journal of Psychiatry, 163, 1019-1025. 